\title{
Response characteristics of soil moisture to rainfall for a single grass vegetation in the urban area $\mathrm{A}$ case of regional grassland in Yangzhou City
}

\author{
Jinbai Huang ${ }^{1}$, Jiawei Wen ${ }^{1}$, Chaofan $\mathrm{Zhu}^{1}$, and Diwen Luo ${ }^{1}$ \\ ${ }^{1}$ Yangzhou University
}

March 25, 2021

\begin{abstract}
A regional grassland with Bermudagrass in Yangzhou City of China was adopted as the study location. Based on the analysis of the different rainfall events and soil water content data in the same periods, the response characteristics of infiltration to rainfall were revealed in a certain degree. The surface resistance parameters ( $\mathrm{rs}$ ) are calibrated according to the soil water content at the depths of a range for 0-30 cm and of the root layer $(0-10 \mathrm{~cm})$. Penman-Monteith (P-M) equation was adopted to estimated the hourly evapotranspiration (ET) over the Bermudagrass lawn of the soil layers for the depths of 0-30 cm (ET30) and 0-10 cm (ET10), respectively. Applicability of HYDRUS-1D model for simulating soil water content at different depths was validated. The results indicated that the infiltration depth generally varies with the rainfall event grade, and on the whole, the infiltration depth increases with the improvement of amount of rainfall; the response time for the soil water content in root layer is much shorter with the less soil water content in the topsoil $(0-5.5 \mathrm{~cm})$; the increase rate of soil water content raised with increasing of rainfall intensity in the state of unsaturation; ET10 accounts for about $78 \%$ of ET30, which demonstrates the water consumed by ET is mainly provided by the soil water in the root layer. the rationality of the results of different rainfall events and infiltration depth achieved by the analysis of the observed data were verified via numerical simulation using Hydrus-1D.
\end{abstract}

\section{Hosted file}

Main_document.pdf available at https://authorea.com/users/403897/articles/515211-responsecharacteristics-of-soil-moisture-to-rainfall-for-a-single-grass-vegetation-in-the-urbanarea-a-case-of-regional-grassland-in-yangzhou-city 